\title{
Benign acute childhood myositis complicating influenza $B$ infection in a boy with idiopathic nephrotic syndrome
}

\author{
PIOTR SKRZYPCZYK, JOANNA PRZYCHODZIEŃ, MAŁGORZATA PAŃCZYK-TOMASZEWSKA
}

Department of Pediatrics and Nephrology, Medical University of Warsaw, Poland

\begin{abstract}
Introduction: Benign acute childhood myositis (BACM) is an acute complication of an infection characterized by calf pain, limitation of lower limb mobility, an increase in serum creatine kinase, and a self-limiting course. No reports of BACM in children with idiopathic nephrotic syndrome (INS) can be found in the literature.

Case report: A 5-year-old boy with steroid-sensitive INS presented with fever, leg pain, and problems with walking. Physical examination showed pharyngeal erythema, preserved movements in all joints, and weakness of leg muscles. Laboratory tests showed white blood cell count 3900/ul, albumin $2.3 \mathrm{~g} / \mathrm{dl}$, urea $25 \mathrm{mg} / \mathrm{dl}$, creatinine $0.3 \mathrm{mg} / \mathrm{dl}$, increased transaminases (AspAT $440 \mathrm{U} / \mathrm{l}$, AlAT $100 \mathrm{U} / \mathrm{l}$ ) and creatine kinase (10 $817 \mathrm{U} / \mathrm{l})$, and proteinuria $3500 \mathrm{mg} / \mathrm{dl}$. The boy was diagnosed with an INS bout and BACM. Testing for infective causes of myositis showed evidence of an influenza B virus infection. Treatment included prednisone and oseltamivir. A rapid improvement of motor function was observed, with normalization of serum creatine kinase and transaminases, and resolution of proteinuria.

Conclusions: 1. As influenza virus infection in a child with INS is a risk factor for complications and a disease bout, these patients should be vaccinated against influenza. 2. Differential diagnosis of leg pain and mobility limitation in a child with INS should include lower limb deep venous thrombosis, arthritis, post-infectious neurological complications (including Guillain-Barré syndrome), and BACM. 3. Serum creatine kinase level should be measured in all cases of motor disturbances in a child with symptoms of respiratory tract infection.
\end{abstract}

Key words: children, nephrotic syndrome, benign acute childhood myositis.

(Cent Eur J Immunol 2016; 41 (3): 328-331)

\section{Introduction}

Nephrotic syndrome is characterized by nephrotic range proteinuria (defined as urine protein : creatinine ratio $\geq 2000 \mathrm{mg} / \mathrm{g}$ ) and hypoalbuminemia (serum albumin level $\leq 2.5 \mathrm{~g} / \mathrm{dl}$ ), most commonly associated with hyperlipidemia and edema [1]. The most common cause of nephrotic syndrome in the pediatric population is idiopathic nephrotic syndrome (INS), present in $90 \%$ of children with nephrotic syndrome diagnosed between 1 and 10 years of age and in $50 \%$ of children with the diagnosis made at the age of $>10$ years [2,3]. Infections, particularly viral infections of the airways, are common factors precipitating the initial and recurrent bouts of the disease.

Influenza is an acute airway disease caused by an infection with influenza A or B virus, an RNA virus of the Orthomyxoviridae family. A high risk of influenza complications is seen in certain groups including children, par- ticularly below 2 years of age, subjects $>65$ years of age, patients with chronic disease (including kidney disease), those receiving immunosuppressive treatment, and obese subjects [4]. Complications include dehydration, otitis media, pneumonia, croup, bronchitis or less commonly bronchiolitis, myelitis, encephalitis, and aseptic meningitis, Guillain-Barré syndrome, seizures (including febrile), secondary bacterial infection, most commonly with Staphylococcus aureus [5], and myocarditis. Myopathy, including influenza-associated benign acute childhood myositis (IA-BACM), is found in up to $33.9 \%$ of influenza B cases and $5.5 \%$ of influenza A cases [6].

The aim the article is to draw attention to possible complications in children with idiopathic nephrotic syndrome illustrated by the example of a case of benign acute childhood myositis in the course of influenza B in a boy with idiopathic nephrotic syndrome.

Correspondence: Piotr Skrzypczyk, Department of Pediatrics and Nephrology, Medical University of Warsaw, Żwirki i Wigury 63 A, 02-091 Warsaw, Poland, e-mail: pskrzyp@gmail.com Submitted: 23.06.2016; Accepted: 09.09.2016 


\section{Case report}

A 5-year-old boy with steroid-sensitive INS was admitted to a hospital due to fever, leg pain, and difficulties with walking.

The initial bout of INS occurred at the age of 2 years and 4 months. Before the present hospitalization, 4 bouts of the disease occurred (including 2 complicating an airway infection, one following allergen exposure, and one without a discernible cause). The patient was treated with prednisone only, and did not receive glucocorticosteroids for the last 4 months.

History taking revealed fever up to $38.6^{\circ} \mathrm{C}$ at 3 days before admission, with resolution of fever on the next day, followed by symmetrical leg pain, and the boy stopped walking due to pain. On admission, evidence of viral pharyngitis was found on the physical examination. Skin of the lower limbs was not affected, there was no limb edema including joint swelling, and no generalized edema was found. On neurological examination, normal muscle strength and tone were found, lower limb motor reflexes were symmetrical and brisk, and no pyramidal or extrapyramidal signs were found, consistent with no evidence of a neurological cause of the symptoms. Laboratory tests showed a decreased white blood cell count $\left(3900 / \mathrm{mm}^{3}\right)$ with neutropenia $\left(1400 / \mathrm{mm}^{3}\right)$, normal hemoglobin level $(12.8 \mathrm{~g} / \mathrm{dl})$, and normal platelet count $\left(226,000 / \mathrm{mm}^{3}\right)$, elevated transaminase level with an increased AspAT (aspartate transaminase) : AlAT (alanine transaminase) ratio (AspAT 440 U/l, AlAT 100 U/1), markedly elevated creatine kinase (CK) level (10817 U/l, reference range 30-150 U/l), hypoproteinemia (total protein $4.9 \mathrm{~g} / \mathrm{dl}$ ) with hypoalbuminemia (albumin $2.3 \mathrm{~g} / \mathrm{dl}$ ), hypertriglyceridemia $(306 \mathrm{mg} / \mathrm{dl}$ ) with normal total cholesterol level $(150 \mathrm{mg} / \mathrm{dl})$, normal C-reactive protein (CRP) level $(<0.5 \mathrm{mg} / \mathrm{dl})$, normal renal function parameters (creatinine $0.3 \mathrm{mg} / \mathrm{dl}$, urea $24 \mathrm{mg} / \mathrm{dl}$ ), and normal electrolytes (sodium $138 \mathrm{mmol} / \mathrm{l}$, potassium $4.5 \mathrm{mmol} / \mathrm{l}$ ). Coagulation parameters included normal international normalized ratio (INR 1.00), slightly increased activated partial thromboplastin time $(42.66 \mathrm{~s}$, reference range $28-40 \mathrm{~s})$, normal fibrinogen level $(2.87 \mathrm{~g} / \mathrm{l})$, and slightly increased D-dimer level $(1723.12 \mu \mathrm{g} / \mathrm{l})$. All tests for autoimmune inflammatory connective tissue disorders were within normal limits [C3 - $122 \mathrm{mg} / \mathrm{dl}$ (reference range $88-165 \mathrm{mg} / \mathrm{dl}), \mathrm{C} 4-41.4 \mathrm{mg} / \mathrm{dl}(14-44 \mathrm{mg} / \mathrm{dl})$, total IgA $173.9 \mathrm{mg} / \mathrm{dl}(38-235 \mathrm{mg} / \mathrm{dl}), \mathrm{IgM} 123.6 \mathrm{mg} / \mathrm{dl}$ (36-198 mg/dl), rheumatoid factor $<8.6 \mathrm{IU} / \mathrm{ml}(<12 \mathrm{IU} / \mathrm{ml})$, antistreptolysin $\mathrm{O}<25 \mathrm{IU} / \mathrm{ml}(<200 \mathrm{IU} / \mathrm{ml})$, antinuclear and anti-neutrophil cytoplasmic antibodies (both negative)] except for lowered total IgG level - $502.3 \mathrm{mg} / \mathrm{dl}$ (853$1440 \mathrm{mg} / \mathrm{dl}$ ). Urinalysis revealed yellow urine with proteinuria $3500 \mathrm{mg} / \mathrm{dl}$ and erythrocyturia 4-6 per field of view. Lower limb imaging studies (X-ray and ultrasonography, including Doppler evaluation) showed no abnormalities. Due to the high CK level, testing for infective causes of myositis was performed, showing evidence of influenza B virus infection (nasopharyngeal swab, PCR RNA testing), and acute Epstein-Barr virus, cytomegaly virus, Chlamydophila pneumoniae, and Mycoplasma pneumoniae infection was excluded by serological testing. Treatment included prednisone $60 \mathrm{mg} / \mathrm{m}^{2} / 24$ hours (started on the first day of the hospital stay) and oseltamivir $45 \mathrm{mg}$ twice daily (started on the second day of the hospital stay following confirmation of the influenza virus infection and continued for 5 days). A rapid improvement of the symptoms of airway infection and motor function was observed, with reduction of serum creatine kinase, transaminase levels, and proteinuria (Table 1). Proteinuria resolved on the eighth day of the hospital stay.

\section{Discussion}

Lower limb pain in a child with nephrotic syndrome is always an alerting symptom and requires extensive diagnostic work-up.

Taking into account multiple risk factors for thrombotic complications in children with INS (hemoconcentration, increased platelet count and activity, urinary loss of coagulation inhibitors including plasminogen, antithrombin III, and C and S proteins, hyperfibrinogenemia, reduced plasminogen activator activity [7]), lower limb venous thrombosis should be excluded $[8,9]$. In the reported case, thrombosis might have been suggested by an elevated D-dimer level, but the clinical presentation was not consistent with this diagnosis (bilateral leg pain, no edema and lower limb skin discoloration), and Doppler ultrasound was normal.

Table 1. Selected biochemical parameters in a boy with idiopathic nephrotic syndrome and benign acute childhood myositis complicating an influenza B virus infection

\begin{tabular}{lcccc}
\hline Parameter & \multicolumn{4}{c}{ Days of hospital stay } \\
\cline { 2 - 5 } & $\mathbf{1}$ & $\mathbf{3}$ & $\mathbf{7}$ & $\mathbf{8}$ \\
\hline CK [U/l] & 10817 & 1079 & 47 & - \\
\hline AspAT [U/l] & 440 & 216 & 28 & - \\
\hline AlAT [U/l] & 100 & 103 & 40 & 0 \\
\hline Proteinuria [mg/dl] & 3500 & 130 & 36 & \\
\hline
\end{tabular}

CK-creatine kinase; AlAT - alanine transaminase; AspAT-aspartate transaminase 
Due to concomitant symptoms of an airway infection, the differential diagnosis needed to include post-infectious neurological complications. Neurological examination showed normal muscle strength and tone, symmetrical, brisk lower limb motor reflexes, and no pyramidal or extrapyramidal signs, and thus it did not indicate any neurological disease including Guillain-Barré syndrome, post-infectious cerebellar ataxia, or neuroinfection. Differential diagnosis of acute motor disturbances also includes arthritis including juvenile idiopathic arthritis, dermatomyositis, muscle dystrophies, trichinosis, steroid-induced avascular necrosis of the femoral head, and posttraumatic changes.

Clinical manifestations together with normal findings of the knee and hip X-ray and ultrasonography together with a high CK level (10 $817 \mathrm{U} / \mathrm{l})$ indicated that the patient's complaints were related to myositis and not arthritis. We looked for infective causes of myositis, and a nasopharyngeal swab for influenza was performed, confirming influenza B virus infection. Thus, the diagnosis of IA-BACM was made.

Benign acute childhood myositis was first described by Lundberg in 1957 under the name of myalgia cruris epidemica [10]. The disease is characterized by an acute pain in the affected muscles (mostly calf muscles) with motor impairment. Pain increases with limb dorsiflexion [11-13]. This complication is twice as common in boys, usually aged 6-9 years $[11,14,15]$. A genetic predisposition to IA-BACM may exist, as evidenced by recurrences reported in the literature $[11,12]$ and disease occurrences in siblings [11, 12]. Myositis more frequently complicates influenza B than A. Hu et al. reported this complications in as many as $33.9 \%$ of children with influenza B and $5.5 \%$ of children with influenza A [6]. Initial symptoms usually occur 3 days (range 0-18 days) after the first symptoms of influenza [14]. Management of BACM includes rest and non-steroidal anti-inflammatory drugs [11].

Myositis may also complicate other viral infections including herpes [16], enterovirus [17], HIV [18], measles [19], Dengue virus [13], and even Mycoplasma pneumoniae infection [20]. It is also believed that use of immunostimulant drugs including inosine pranobex $[11,21]$ may be a predisposing factor. Muscle biopsy shows degenerative changes, focal myofibril vacuolization, and myonecrosis [13]. Postulated mechanisms of muscle damage include direct microorganism invasion into myocytes, damage induced by viral toxins, and immune reactions caused by cytokine storm [22]. Desdouits et al. observed the presence of sialic acid receptors on skeletal muscle cells. Using these receptors, influenza virus penetrates airway epithelial cells. The same authors also reported viral replication in rhabdomyocytes with resultant cell destruction [23].

The disease is characterized by a self-limiting course and a typical configuration of biochemical parameters, including elevated creatine kinase and transaminase levels with normal inflammatory parameters [11]. Creatine kinase and aspartate transaminase levels seen in our patient are among the highest reported in the literature in BACM cases [12, 24-26].

Although most cases of IA-BACM are characterized by a mild, self-limiting course, the disease may sometimes lead to massive rhabdomyolysis (3\% of IA-BACM cases) manifesting with myoglobinuria and renal failure (80\% of patients with rhabdomyolysis). Rhabdomyolysis is more common in girls (80\%) and in influenza A (86\%) [14].

Children with INS are characterized by a high risk of infective complications. Factors predisposing to infections in this patient group include urinary loss of $\mathrm{IgG}$ immunoglobulins and complement factors B, D, and I [27-29], $\mathrm{T}$ cell function abnormalities [30], particularly involving regulatory $\mathrm{T}$ cell (Treg) subpopulations [31], and immunosuppressive treatment used in these patients. Reports of severe influenza virus infections in children with INS were published in the literature [32], but IA-BACM was not reported in these patients. It has also been known for a long time that viral infections, including influenza A, may induce disease bouts in these patients [33]. On the other hand, Kimata et al. reported a case of disease remission induced by influenza B virus in a 5-year-old boy with an initial bout of INS [34]. The authors believed that remission was associated with viral stimulation of Treg cells [34], as shown by cytometry.

According to the 2016 immunization schedule in Poland, immunization against influenza is recommended in children with recurrent nephrotic syndrome [35]. Poyrazoğlu et al. reported that influenza A vaccination effectively induced protective antibody titers in this patient group [36]. Although it is known that INS bouts may occur following immunization [37], the authors found no association between influenza vaccination and the rate of disease recurrence [36].

In the reported case, INS present in our patient prompted us to initiate specific antiviral therapy with oseltamivir. Moon et al. described 5 patients with myositis complicating influenza B virus infection, 4 of whom were treated with oseltamivir without any complications [38]. Currently, there is no clear evidence of benefits of oseltamivir therapy in the case of neurological or muscle complications. Use of oseltamivir combined with full-dose prednisone allowed rapid remission in the reported patient.

\section{Conclusions}

As influenza virus infection in a child with INS is a risk factor for complications and a disease bout, these patients should be vaccinated against influenza.

Differential diagnosis of leg pain and mobility limitation in a child with INS should include lower limb deep venous thrombosis, arthritis, post-infectious neurological complications (including Guillain-Barré syndrome), and BACM. 
Serum creatine kinase level should be measured in all cases of motor disturbances in a child with symptoms of respiratory tract infection.

The authors declare no conflict of interest.

\section{References}

1. Kidney Disease: Improving Global Outcomes (KDIGO) Glomerulonephritis Work Group (2012): KDIGO Clinical Practice Guideline for Glomerulonephritis. Kidney Int Suppl 2: 139-274.

2. Lombel RM, Hodson EM, Gipson DS; Kidney Disease: Improving Global Outcomes (2013): Treatment of steroid-resistant nephrotic syndrome in children: new guidelines from KDIGO. Pediatr Nephrol 28: 409-414.

3. A report of the International Study of Kidney Disease in Children (1978): Nephrotic syndrome in children: prediction of histopathology from clinical and laboratory characteristics at time of diagnosis. Kidney Int 13: 159-165.

4. Centers for Disease Control and Prevention (CDC) (2013): Prevention and control of seasonal influenza with vaccines. Recommendations of the Advisory Committee on Immunization Practices-United States, 2013-2014. MMWR Recomm Rep 62: 1-43.

5. Dawood FS, Chaves SS, Pérez A, et al.; Emerging Infections Program Network (2014): Complications and associated bacterial coinfections among children hospitalized with seasonal or pandemic influenza, United States, 2003-2010. J Infect Dis 209: 686-694.

6. Hu JJ, Kao CL, Lee PI, et al. (2004): Clinical features of influenza A and B in children and association with myositis. J Microbiol Immunol Infect 37: 95-98.

7. Singhal R, Brimble KS (2006): Thromboembolic complications in the nephrotic syndrome: pathophysiology and clinical management. Thromb Res 118: 397-407.

8. Egli F, Elmiger P, Stalder G (1973): Thrombosis as a complication of nephrotic syndrome. Helv Paediatr Acta 30 (Suppl): 20-21.

9. Kerlin BA, Blatt NB, Fuh B, et al. (2009): Epidemiology and risk factors for thromboembolic complications of childhood nephrotic syndrome: a Midwest Pediatric Nephrology Consortium (MWPNC) study. J Pediatr 155: 105-110.

10. Lundberg A (1957): Myalgia cruris epidemica. Acta Pediatr 46: $18-31$.

11. Hozyasz KK, Gryglicka H, Radomyska B (2009): Benign acute childhood myositis (BACM) - cases report. Pol Merkur Lekarski 27: 129-131.

12. Mackay MT, Komberg AJ, Shield LK, Dennett X (1999): Benign acute childhood myositis: laboratory and clinical features. Neurology 53: 2127-2131.

13. Rajajee S, Ezhilarasi S, Rajarajan K (2005): Benign acute childhood myositis. Indian J Pediatr 72: 399-400.

14. Agyeman P, Duppenthaler A, Heininger U, Aebi C (2004): Influenza-associated myositis in children. Infection 32: 199-203.

15. Mall S, Buchholz U, Tibussek D, et al. (2011): A large outbreak of influenza B-associated benign acute childhood myositis in Germany, 2007/2008. Pediatr Infect Dis J 30: 142-146.

16. Schlesinger JJ, Gandara D, Bensch KG (1978): Myoglobinuria associated with herpes-group viral infections. Arch Intern Med 138: 422-424.
17. Meshkinpour H, Vaziri ND (1982): Association of myoglobinuria with adenovirus infection. West J Med 137: 130-132.

18. Guillaume MP, Van Beers D, Delforge ML, et al. (1995): Primary human immunodeficiency virus infection presenting as myopericarditis and rhabdomyolysis. Clin Infect Dis 21: 451-452.

19. Seibold S, Merkel F, Weber M, Marx M (1998): Rhabdomyolysis and acute renal failure in an adult with measles virus infection. Nephrol Dial Transplant 13: 1829-1831.

20. Belardi C, Roberge R, Kelly M, Serbin S (1987): Myalgia cruris epidemica (benign acute childhood myositis) associated with Mycoplasma pneumoniae infection. Ann Emerg Med 16: 579-581.

21. Chuck AJ, Lloyd Jones JK, Dunn NA (1988): Is inosine pranobex contraindicated in autoimmune disease? Br Med J (Clin Res Ed) 296: 646.

22. Fadila MF, Wool KJ (2015): Rhabdomyolysis secondary to influenza A infection: a case report and review of the literature. N Am J Med Sci 7: 122-124.

23. Desdouits M, Munier S, Prevost MC, et al. (2013): Productive infection of human skeletal muscle cells by pandemic and seasonal influenza A(H1N1) viruses. PLoS One 8: e79628.

24. Karpathios T, Kostaki M, Drakonaki S, et al. (1995): An epidemic with influenza $B$ virus causing benign acute myositis in ten boys and two girls. Eur J Pediatr 154: 334-336.

25. Sonmez F, Cakir M, Yayla S, Boz C (2004): Benign acute childhood myositis. Med Princ Pract 13: 227-229.

26. King BA (2003): Benign acute childhood myositis as a cause of failure to weight bear. J Paediatr Child Health 39: 378-380.

27. Matsell DG, Wyatt RJ (1993): The role of I and B in peritonitis associated with the nephrotic syndrome of childhood. Pediatr Res 34: 84-88.

28. Spika JS, Halsey NA, Fish AJ, et al. (1982): Serum antibody response to pneumococcal vaccine in children with nephrotic syndrome. Paediatrics 69: 219-223.

29. Yetgin S, Gur A, Saatci U (1980): Non-specific immunity in nephrotic syndrome. Acta Paediatr Scand 69: 21-24.

30. Shalhoub RJ (1974): The pathogenesis of lipoid nephrosis: a disorder of T-cell function. Lancet 2: 556-560.

31. Araya C, Diaz L, Wasserfall C, et al. (2009): T regulatory cell function in idiopathic minimal lesion nephrotic syndrome. Pediatr Nephrol 24: 1691-1698.

32. Fujinaga S, Hara T (2015): Acute kidney injury following plastic bronchitis associated with influenza B virus in a child with nephrotic syndrome. Indian Pediatr 52: 523-525.

33. MacDonald NE, Wolfish N, McLaine P, et al. (1986): Role of respiratory viruses in exacerbations of primary nephrotic syndrome. J Pediatr 108: 378-382.

34. Kimata T, Tsuji S, Kino J, et al. (2013): Close association between proteinuria and regulatory $\mathrm{T}$ cells in patients with idiopathic nephrotic syndrome. Pediatr Nephrol 28: 667-669.

35. http://gis.gov.pl/images/ep/akt-1pso2016.pdf

36. Poyrazoğlu HM, Düşünsel R, Gündüz Z, et al. (2004): Antibody response to influenza A vaccination in children with nephrotic syndrome. Pediatr Nephrol 19: 57-60.

37. Işlek I, Cengiz K, Cakir M, Küçüködük S (2000): Nephrotic syndrome following hepatitis B vaccination. Pediatr Nephrol 14: $89-90$

38. Moon JH, Na JY, Kim JH, et al. (2013): Neurological and muscular manifestations associated with influenza $b$ infection in children. Pediatr Neurol 49: 97-101. 